\title{
Daya Inovasi Pada Kinerja Karyawan
}

\author{
Ferri Kuswantoro \\ Fakultas Ekonomi Universitas Janabadra Yogyakarta \\ Jl. Tentara Rakyat Mataram No.58, Bumijo, Kec. Jetis, Kota Yogyakarta, \\ Daerah Istimewa Yogyakarta 5523, Indonesia
}

Correspondence: Ferri Kuswantoro (ferri@janabadra.ac.id)

Received: 050721 - Revised: 220721 - Accepted: 080821 - Published: 280921

\begin{abstract}
Abstrak. Inovasi merupakan pendukung utama khusunya dalam peningkatan kinerja karyawan. Banyak studi telah menjelaskan pentingnya pelatihan dan kerja tim di dalam mengupayakan pertumbuhan. Namun studi bagaimana peran daya inovasi dalam mendorong hubungan antara pelatihan dan kerja tim terhadap kepuasan kerja karyawan masih belum awam di jelaskan. Tujuan dari pada penelitian ini adalah untuk mengetahui peran daya inovasi di dalam mendorong hubungan antara pelatihan dan kerja tim terhadap kepuasan kerja karyawan. Menggunakan sampel sebanyak 165 responden dengan kuesioner skala 7 yang terdiri dari karyawan secara umum serta dukungan AMOS versi 24 hasil penelitian menunjukkan bahwa terdapat pengaruh positif signifikan antara kerja tim terhadap daya inovasi dan kepuasan kerja karyawan. Terdapat pengaruh positif signifikan antara hubungan daya inovasi terhadap kepuasan kerja karyawan. Sedangkan tidak terdapat pengaruh positif signifikan antara pelatihan manajerial terhadap daya inovasi dan kepuasan kerja karyawan. Hasil akhir menjelaskan bahwa daya inovasi memediasi postif signifikan antara hubungan kerja tim terhadap kepuasan kerja karyawan.
\end{abstract}

Kata kunci: Daya, inovasi, kinerja karyawan

Citation Format: Kuswantoro, F. (2021). Daya Inovasi Pada Kinerja Karyawan. Prosiding Seminar Nasional Abdimas Ma Chung (SENAM), 2021, 194-202 


\section{PENDAHULUAN}

\section{Latar Belakang}

Daya inovasi merupakan dukungan utama dalam membantu pemberdayaan aktifitas ekonomi dan kehidupan yang lebih bermanfaat (Kent,2012). Kemampuan berinovasi dalam aktifitas professional kerja akan membawa kepada hasil untuk kepuasan kerja yang akan berpengaruh signifikan terhadap kinerja kerja karyawan (Saputra, 2018). Keterlibatan dalam penggunaan teknologi informasi menurut Yam, dkk (2014) akan memperkaya sumber daya inovasi yang akan memberikan dorongan di dalam pencapaian volume omset penjualan sehingga memperjelas rasa keadaan kepuasan kerja.

Pelatihan dan kerja tim merupakan dua faktor penting di dalam memperhatikan kepuasan kerja karyawan. Menurut Zehra, (2016) program pelatihan akan mebantu karyawan di dalam membawa perilaku positif dan professional yang akan mendorong peningkatan kepuasan kerja pencapaian omzet yang lebih tinggi. Faridi, dkk (2017) mengemukakan bahwa pelaksanaan program pelatihan dan pengembangan selalu bertujuan secara signifikan untuk peningkatan kepuasan kerja. Hal lain yang tidak kalah penting adalah kerja tim. Kerja tim di perlukan untuk semua usaha dalam setiap kerja. Kerja tim di indikasikan signifikan positif dalam pencapaian tujuan tim yang akan memberikan perasaan positif akan hasil kerja (Sobia, dkk 2014). Devina (2018) menegaskan bahwa kerja tim mampu untuk mempengaruhi secara signifikan penanganan kerja sesuai harapan tim kerja.

Daya inovasi juga di pengaruhi oleh pelatihan dan kerja tim di tempat aktifitas kerja. Dostie (2018) menjelaskan bahwa pelaksanaan pelatihan akan memandu pada daya inovasi. Andreas, dkk (2016) juga menjelaskan bahwa perilaku untuk berinovasi dapat di motivasi oleh pelatihan kerja secara tim. Saling berkontribusi dan mendukung sesama pelaku tim kerja akan berdampak pada perilaku kerja yang inovatif. Doris, dkk (2014) peningkatan aktivitas kerja tim akan memperdayakan kreativitas yang akan meningkatkan tingkat daya inovasi.

\section{Tujuan Penelitian}

Seperti yang sudah di jelaskan sebelumnya bahwa pelatihan dan kerja tim berperan secara signifikan dan positif terhadap daya inovasi dan kepuasan kerja. Melihat hubungan yang penting antara daya inovasi terhadap kepuasan kerja maka tujuan penelitian ini adalah 
untuk mengkaji peran daya inovasi akan hubungan antara pelatihan dan kerja tim terhadap kepuasan kerja.

\section{METODOLOGI PENELITIAN}

\section{Sumber Data}

Penelitian sebelumnya di lakukan oleh Kuswantoro Dan Rosli (2012) serta Halil, dkk (2015) mengenai penelitian kuantitatif. Menggunakan kuesioner dengan metode random sampling terdiri dari 7 (tujuh) skala likert jumlah sampel responden adalah 165 karyawan secara umum dari berbagai sektor di Wilayah Daerah Istimewa Yogyakarta. Kuesioner di distribusikan sebagian besar disampaikan oleh survei dan pertemuan tatap muka dengan responden.

\section{Pengukuran Variabel}

Acuan dalam penyusunan kuesioner untuk masing-masing konstrak variabel adalah seperti pada tabel 1 sebagai berikut :

\section{Tabel 1}

\section{Dimensi Variabel}

\begin{tabular}{|c|c|c|c|c|}
\hline No & Variabel & & Item & Pustaka Acuan \\
\hline 1. & Pelatihan & $\begin{array}{l}1.2 \\
1.3\end{array}$ & $\begin{array}{l}\text { Terdapat program pelatihan dalam } \\
\text { meningkatkan pengetahuan untuk operasional } \\
\text { kerja } \\
\text { Terdapat kaderisasi dari atasan kepada staf } \\
\text { kerja } \\
\text { Adanya program menempuh jenjang } \\
\text { Pendidikan yang lebih tinggi }\end{array}$ & $\begin{array}{l}\text { Faridi, dkk } \\
\text { (2017) }\end{array}$ \\
\hline 2. & Kerja Tim & $\begin{array}{l}2.1 \\
2.2\end{array}$ & $\begin{array}{l}\text { Saling membantu meringankan beban kerja } \\
\text { dalam tim } \\
\text { Saling memonitor jalannya operasional tim } \\
\text { kerja }\end{array}$ & $\begin{array}{l}\text { Andreas, dkk } \\
\text { (2016) }\end{array}$ \\
\hline 3. & Daya Inovasi & $\begin{array}{l}3.1 \\
3.2\end{array}$ & $\begin{array}{l}\text { Menggunakan metode yang kreatif dalam } \\
\text { pelaksanaan kerja } \\
\text { Memanfaatkan teknologi dalam penyelesaian } \\
\text { kerja }\end{array}$ & Doris, dkk (2014) \\
\hline 4. & $\begin{array}{l}\text { Kepuasan } \\
\text { Kerja }\end{array}$ & $\begin{array}{l}4.1 \\
4.2 \\
4.3\end{array}$ & $\begin{array}{l}\text { Pekerjaan yang di jalani memiliki arti penting } \\
\text { Kompensasi dalam kerja selalu memberikan } \\
\text { motivasi } \\
\text { Selalu antusias dalam bekerja }\end{array}$ & $\begin{array}{l}\text { Chaturvedi Dan } \\
\text { Raavi.(2018). }\end{array}$ \\
\hline
\end{tabular}

\section{Analisis Data}


Data primer dikumpulkan dengan menggunakan kuesioner, setelah itu, untuk data dilakukan dengan beberapa langkah. Langkah-langkah ini adalah mengedit, memasukkan, dan menganalisis. Bantuan paket statistik untuk ilmu sosial (SPSS) 24 digunakan untuk memproses data untuk menguji validitas, reliabilitas, dan normalitas. Dan AMOS 24 untuk mengkaji analisa pengaruh dan peran daya inovasi sebagai variabel mediasi.

\section{ANALISA DAN PEMBAHASAN}

\section{Deskripsi Responden}

Seperti terlihat pada tabel 2 berikut sampel dengan jumlah 165 responden di jelaskan secara deskriptif dengan mayoritas katagori usia di bawah 25 tahun atau sebesar 41,2\% di ikuti oleh usia diatas 45 tahun minoritas dengan jumlah proporsi 4,8\%. Kemudian dari segi pendidikan responden sebagian besar lulusan SLTA atau SMU dengan jumlah 69 responden dengan proporsi 41,80 \% di ikuti minoritas oleh lulusan S3 dengan jumlah 1 responden. Berdasarkan gender laki-laki dan perempuan masing-masing berjumlah 56 responden lakilaki dan 109 perempuan atau masing-masing 33,90\% perempuan dan 109 atau 66,10\%. Untuk status kerja mayoritas sampel adalah karyawan tetap dengan jumlah 84 responden atau 50,90\% di ikuti oleh paling minoritas adalah lainnya selain status tetap,kontrak, dan honorer berjumlah 3 responden atau 1,80\%. Dan untuk jenis bagian pekerjaan sebagian besar bekerja di departemen keuangan dan sektor lainnya dengan jumlah 40 responden atau berkisar 24,20\% di ikuti paling sedikit dari departemen jasa kebersihan dengan jumlah 11 responden.

Tabel 2. Respondent Profiles

\begin{tabular}{clccc}
\hline No & \multicolumn{1}{c}{ Keterangan } & Frekwensi & Persen $(\%)$ & Kumulatif Persen (\%) \\
\hline 1. & Usia Karyawan : & & & \\
& Di bawah 25 tahun & 68 & 41.2 & 41.2 \\
& (25-30) tahun & 42 & 25.5 & 66.7 \\
(31-35) tahun & 16 & 9.7 & 76.4 \\
(36-40) tahun & 18 & 10.9 & 87.3 \\
(41-45) tahun & 13 & 7.9 & 95.2 \\
& Di atas 45 tahun & 8 & 4.8 & $100 \%$ \\
2. & 165 & $100 \%$ & \\
Tingkat Pendidikan : & & & \\
SLTA & 69 & 41.8 & 51.8 \\
D3 & 22 & 13.3 & 55.2 \\
S1 & 67 & 40.6 & 95.8 \\
S2 & 6 & 3.6 & 99.4 \\
S3 & 1 & 0.6 & $100 \%$ \\
Gender : & 165 & $100 \%$ & \\
Laki-laki & 56 & & 33,9
\end{tabular}




\section{Perempuan}

4. Status Kerja :

Tetap

Kontrak

Honorer

Lainnya

5. Bagian Kerja :

Pemasaran

Produksi

Keuangan

Umum

Sumber daya manusia

Kebersihan

Lainnya

\section{9}

165

84

66

12

3

165

\section{4}

12

40

15

13

11

40

165
66, 1

$100 \%$

50,9

40,0

7,3

1,8

$100 \%$

20,6

7,3

24,2

9, 1

7,9

6,7

24,2

$100 \%$
$100 \%$

50,9

90,9

98,2

$100 \%$

20,6

27,9

52,1

61,2

69,1

75,8

$100 \%$

Uji sampel sebanyak 165 responden. Tingkat signifikansi jika probabilitas $<0,05$ maka pernyataan tersebut valid. Sedangkan jika nilai probabilitas > 0,05 maka pernyataan tersebut tidak valid (Ghozali, 2009). Seperti pada tabel 3 berikut ini adalah hasil uji validitas di mana semua dimensi variabel adalah valid dengan tingkat signifikansi $0,000<0,05$. Hal yang dilakukan setelah menunjukkan bahwa semua variabel pernyataan layak dijadikan instrumen penelitian adalah melakukan uji sampel besar sebanyak 165 responden. Pernyataan dapat dikatakan reliabel jika nilai cronbach's alpha > 0,6 (Ghozali, 2009).

Tabel 3. Validitas Dan Reliabilitas

\begin{tabular}{|c|c|c|c|c|c|c|c|c|c|c|c|}
\hline \multicolumn{2}{|c|}{ Pelatihan } & $\begin{array}{c}\text { Cron } \\
\text { Alph } \\
a\end{array}$ & \multicolumn{2}{|c|}{ Kerja Tim } & \multirow[t]{2}{*}{$\begin{array}{c}\text { Cron } \\
\text { Alph } \\
\quad \boldsymbol{a}\end{array}$} & \multicolumn{2}{|r|}{$\begin{array}{l}\text { Daya } \\
\text { Inovasi }\end{array}$} & \multirow[t]{2}{*}{$\begin{array}{c}\text { Cron } \\
\text { Alph } \\
\text { a }\end{array}$} & \multicolumn{2}{|c|}{$\begin{array}{c}\text { Kepuasan } \\
\text { Kerja }\end{array}$} & \multirow[t]{2}{*}{$\begin{array}{c}\text { Cron } \\
\text { Alph } \\
\mathbf{a} \\
\end{array}$} \\
\hline $\mathrm{p}$ & $0,878^{*}$ & & $\mathrm{tm}$ & $0,898 *$ & & $\mathrm{i}$ & $0,923^{*}$ & & kep & $0,882^{*}$ & \\
\hline 1 & $*$ & 0,841 & 1 & $*$ & 0,749 & 1 & $*$ & 0,833 & 1 & $*$ & 0,890 \\
\hline $\mathrm{p}$ & $0,870 *$ & & $\mathrm{tm}$ & $0,890 *$ & & $\mathrm{i}$ & $0,928 *$ & & kep & $0,928^{*}$ & \\
\hline 2 & $*$ & & 2 & $*$ & & 2 & $*$ & & 2 & $*$ & \\
\hline $\mathrm{p}$ & $0,866^{*}$ & & & & & & & & kep & $0,910^{*}$ & \\
\hline 3 & $*$ & & & & & & & & 3 & $*$ & \\
\hline
\end{tabular}

Terlepas dari interpretasi grafis dari hasil, normalitas sempurna mungkin juga ditekankan oleh nilai-nilai rasio kurtosis dan skewness (Kim, 2013). Menurut Kim (2013) jika nilai rasio skewness dan kurtosis atau nilai Z terpenuhi kurang dari 3,29 untuk variabel pelatihan, kerja tim, dan kepuasan kerja, artinya normalitas data diterima. Sedangkan untuk 
variable daya inovasi memiliki nilai $\mathrm{Z}$ mendekati katagori layak yaitu : 3,40 untuk $\mathrm{Z}$ skewness value.

Tabel 4. Normalitas

\begin{tabular}{|c|c|c|c|c|c|c|c|c|}
\hline \multirow[b]{2}{*}{ Variables } & \multirow[b]{2}{*}{$\begin{array}{c}N \\
\text { statistic }\end{array}$} & \multirow[b]{2}{*}{$\begin{array}{c}\text { Mean } \\
\text { statistic }\end{array}$} & \multicolumn{2}{|c|}{ Skewness } & \multirow[b]{2}{*}{$Z$ value } & \multicolumn{2}{|c|}{ Kurtosis } & \multirow[b]{2}{*}{ Z value } \\
\hline & & & Statistic & $\begin{array}{c}\text { Std. } \\
\text { error }\end{array}$ & & Statistic & $\begin{array}{c}\text { Std. } \\
\text { error }\end{array}$ & \\
\hline Pelatihan & 165 & 13,78 & 0,016 & 0,189 & 0,084656 & $-0,710$ & 0,376 & $-1,8883$ \\
\hline Daya & 165 & 8,30 & 0,642 & 0,189 & & 0,497 & 0,376 & \\
\hline Inovasi & & & & & 3,396825 & & & 1,321809 \\
\hline Kerja Tim & 165 & 7,63 & $-0,294$ & 0,189 & $-1,55556$ & $-0,712$ & 0,376 & $-1,89362$ \\
\hline Kepuasan & 165 & 12,21 & $-0,778$ & 0,189 & & $-0,110$ & 0,376 & \\
\hline Kerja & & & & & $-4,1164$ & & & $-0,29255$ \\
\hline
\end{tabular}

Seperti terlihat pada tabel 5 untuk uji model penelitian yang terkonsep pada gambar 1, di indikasikan bahwa nilai degree of freedom adalah positif. Artinya bahwa model layak di lanjutkan pada proses analisa pengaruh. Terlihat nilai Goodness Fit Of Index (GFI), Incremental Fit Index (IFI), dan Comparative Fit Index (CFI) adalah > dari 0,90 yang menunjukkan bahwa model penelitian adalah layak.

Tabel 5. Uji Model

\begin{tabular}{lcc}
\hline \multicolumn{1}{c}{ Keterangan } & Nilai Index & Katagori \\
\hline Degree Of Freedom $(D F)$ & +29 & positif \\
Goodness Fit Of Index $(G F I)$ & 0,907 & fit $>0,90$ \\
Incremental Fit Index $(I F I)$ & 0,920 & fit $>0,90$ \\
Comparative Fit Index $(C F I)$ & 0,918 & fit $>0,90$ \\
Probability Level & 0,000 & not fit $<0,050$ \\
\hline
\end{tabular}

Gambar 1. Model Penelitian 


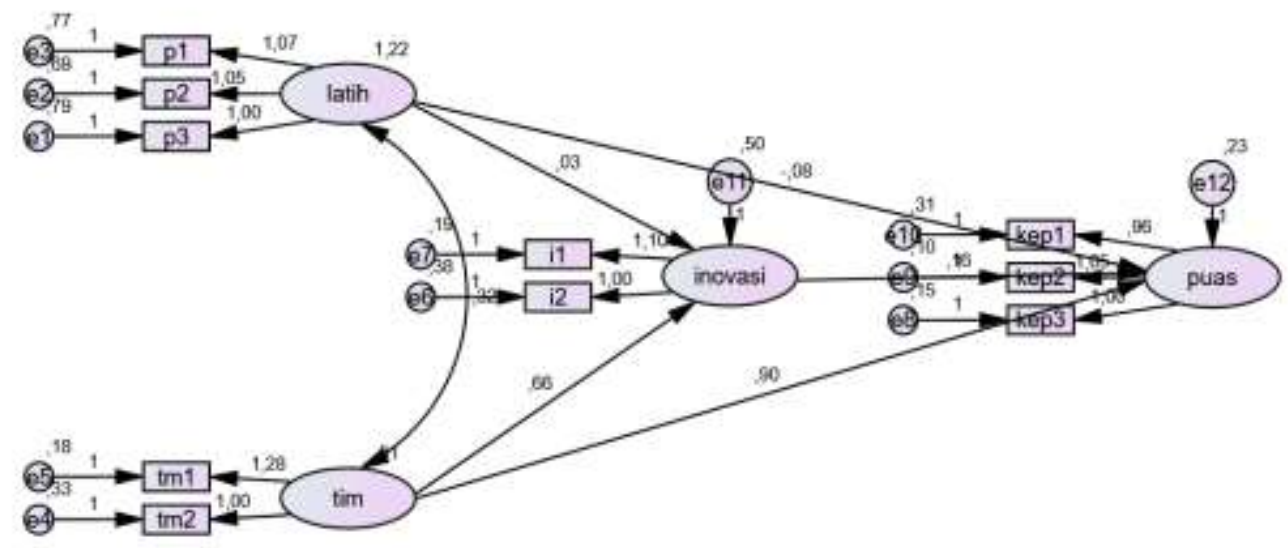

Ket : p1 s.d p3 : konstrak pelatihan; tm1 s.d tm2 : konstrak kerja tim; i1 s.d i2 : konstruk daya inovasi; kep1 s.d kep3 : konstrak kepuasan kerja

Di lihat dari tabel 6 bahwa pengaruh pelatihan terhadap daya inovasi dan kepuasan kerja berpengaruh tidak signifikan dengan di tunjukkan nilai probabilitas $(\mathrm{p})>0,050$. Sedangkan kerja tim berpengaruh secara positif signifikan terhadap daya inovasi dan kepuasan kerja dengan nilai probabilitas < 0,050. Masing-masing memiliki nilai estimasi sebesar 0.661 dan 0,895. Hubungan antara daya inovasi dan kepuasan kerja berpengaruh positif signifikan di tunjukkan dengan nilai $\mathrm{p}<0,050$ dengan nilai estimasi sebesar 0,156. Kemudian pada tabel 6 juga ditunjukkan bahwa pengaruh kerja tim terhadap daya inovasi dan kepuasan kerja adalah positif signifikan dengan nilai $\mathrm{p}<0,050$ dan pengaruh daya inovasi terhadap kepuasan kerja positif signifikan dengan dengan nilai $\mathrm{p}<0,050$, sehingga daya inovasi memediasi secara menyeluruhparsial atau partially mediating hubungan antara kerja tim terhadap kepuasan kerja. Hal tersebut juga di tunjukkan dari tabel 7 yaitu pengaruh tidak langsung antara kerja tim terhadap kepuasan kerja melalui daya inovasi dengan nilai koefisien 0,100. Sedangkan pengaruh pelatihan terhadap daya inovasi dan kepuasan kerja adalah tidak signifikan dengan nilai $\mathrm{p}>0,050$, sehingga daya inovasi memediasi secara penuh atau fully mediating (Syafitri Dan Anjarwati,2016).

Tabel 6. Regression Weights

\begin{tabular}{|c|c|c|c|c|}
\hline Hubungan & Estimate & S.E. & C.R. & $\mathbf{P}$ \\
\hline <--- latih & 0,032 & 0,078 & 0,412 & 0,680 \\
\hline
\end{tabular}




\begin{tabular}{lllcccc}
\hline inovasi & $<---$ & tim & 0,661 & 0,179 & 3,696 & $* * *$ \\
puas & $<---$ & inovasi & 0,156 & 0,079 & 1,984 & 0,047 \\
puas & $<---$ & latih & $-0,078$ & 0,060 & $-1,299$ & 0,194 \\
puas & $<---$ & tim & 0,895 & 0,162 & 5,532 & $* * *$ \\
\hline
\end{tabular}

\section{Pembahasan}

Dari hasil analisa di tunjukkan bahwa kerja tim berpengaruh positif signifikan terhadap daya inovasi tenaga karyawan. Hasil ini juga di dukung oleh studi dari Andreas, dkk (2016) yang menjelaskan bahwa perilaku kerja tim juga akan membuat perilaku inovatif. Perilaku saling berbagi dan meneladani memiliki dampak paling kuat pada keterlibatan tim dalam pengembangan inovasi. Doris, dkk (2014) menambahkan bahwa semakin luas penggunaan kerja tim dalam organisasi mengakibatkan semakin tinggi tingkat inovasi organisasi terutama untuk tim produksi. Lee (2008) menunjukkan bahwa tim kerja pada industri membutuhkan budaya yang inovatif untuk pertumbuhan. Selanjutnya kerja tim memiliki peran penting untuk peningkatan kepuasan kerja karyawan. Jalal Dan Tahir (2015) berpendapat bahwa kerja tim mampu membuat target kerja mencapai kepuasan. Sedangkan Devina (2018) menambahkan kesadaran akan bekerja berdasarkan kekompakan selalu mengakibatkan hasil sesuai yang di harapkan. Sobia, dkk (2014) menekankan bahwa kerja tim di dalam pekerjaan yang berat akan selalu dirasakan ringan oleh semua anggota tim. Terakhir adalah daya inovasi mendorong signifikan positif terhadap kepuasan kerja. Kent, dkk (2017) menunjukkan bahwa daya inovasi mampu membawa keseimbangan antara kepuasan kerja dan kesejahteraan keluarga. Saputra (2018) menunjukkan bahwa kemampuan inovasi akan mempererat daya proses kerja semakin efektif dan efisien. Yam, dkk (2014) menambahkan bahwa keterlibatan teknologi untuk berinovasi dalam proses kerja akan mendorong produktivitas proses admistrasi dan produksi hasil kerja yang akan memberikan hasil seperti yang di harapkan.

\section{KESIMPULAN}

Kemampuan berdaya inovasi merupakan faktor penting dalam peningkatan kepuasan kerja karyawan. Hasil studi ini memberikan penjelasan bahwa kerja tim sangat mendukung dalam peranannya untuk meningkatkan pertumbuhan inovasi dan kepuasan kerja. Oleh karena itu memberdayakan inovasi harus selalu di lanjutkan untuk membuat proses kerja dalam tim lebih berkembang dan akan memberikan kondisi hasil kerja yang di tujukan. Dengan kata lain daya inovasi merupakan mediasi menyeluruh hubungan antara kerja tim 
terhadap kepuasan kerja. Hasil studi ini juga menunjukkan bahwa pelatihan merupakan tambahan yang tidak kalah penting untuk meningkatkan inovasi.

\section{REFERENSI}

Andreas Widmann, Gerhard Messmann, et al. (2016). "The Impact of Team Learning Behaviors on Team Innovative Work Behavior: A Systematic Review." Human Resource Development Review 15(4): 429-458.

Chaturvedi, Mayuri and Sumedha Raavi.(2018). A Study on Employee Job Satisfaction in Different Sectors. International Journal of Scientific Engineering and Research (IJSER), 7(1), 105-108.

Devina, G. (2018). "Pengaruh Teamwork Terhadap Kepuasan Kerja Karyawan Pada Pt. Federal International Finance Cabang Surabaya 2." Jurnal Ilmu Manajemen 6(1).

Dostie, B. (2018). "The Impact Of Training On Innovation." ILR Review 71(1): 64-87.

Doris Fay, Helen Shipton, et al. (2014). "Teamwork and Organizational Innovation: The Moderating Role of the HRM Context." Creativity And Innovation Management 24(2): 261-277.

Faridi, A., Baloch, A., \& Wajidi, A. (2017). Job satisfaction and organizational commitment under Traditional and Modern T\&D program: Evidence from Public Banking Sector of Pakistan, International Journal of Applied Business and Management Studies, 2(1), 9-16.

Ghozali, Imana,(2009). "Analisis multivariate lanjutan dengan program spss." penerbitan universitas diponegoro

Halil, d. Bagus P. Yudhia K, et al. (2015). "Pengaruh Kepemimpinan, Kedisiplinan Dan Motivasi Kerja Terhadap Produktivitas Melalui Kinerja Karyawan (Studi Empiris Pada Perusahaan Daerah Perkebunan (Pdp) Kabupaten Jember)." JEAM 14(2): 4970.

Jalal Hanasyha and A. P. R. Tahir (2015). "Examing The Effect Of Empowerment, Teamwork, And Employee Training On Job Satisfaction " Social And Behavioral Science: 272-282.

Kent Wickstrøm Jensen, A. Ye Liu, et al. (2017). "Entrepreneurs innovation bringing job satisfaction, work-family balance, and life satisfaction: In China and around the world." International Journal of Innovation Studies 1: 193-206.

Kim, Y. and A. Y. C. Cho (2016). "Impact Of Retirement System On Job Satisfaction And Loyalty: A Case Of The Salary Peak System." International Business And Economics Research Journal 15(1): 27-40.

Kuswantoro, F. and a. M. M. Rosli (2012). "Logistics Efficiency and Firm Performance: Evidence from Indonesian Small and Medium Enterprises." American International Journal of Contemporary Research 2(6): 102-111.

Lee, Y.-D. and H.-M. And Chang (2008). "Relations between Team Work and Innovation in Organizations and the Job Satisfaction of Employees: A Factor Analytic Study." International Journal of Management.

Sobia Shujaat, Karachi Amir Manzoor, et al. (2014). "Impact of Team Work on Employee Satisfaction." IBT Journal of Business Studies (FormerlyJournal of Management \& Social Sciences) 10(2): 71-80.

Saputra, T. (2018). "Pengaruh Kemampuan Dan Inovasi Kerja Terhadap Kepuasan Kerja Dan Kinerja Pegawai Pt.Bank Rakyat Indonesia Cabang Pontianak." Jurnal Manajemen Update 7(2). 
Syafitri Rosyida and D. A. L. Anjarwati (2016). "Pengaruh Store Atmosfer Dan Promosi Penjualan Terhadap Pembelian Impulsif Dengan Emosi Positif Sebagai Variabel Intervening." Jurnal Riset Ekonomi dan Manajemen 16(1): 105-127.

Yam B. Limbu , A. Jayachandran, et al. (2014). "Does information and communication technology improve job satisfaction? The moderating role of sales technology orientation." Industrial Marketing Management 1-10.

Zehra, N. (2016), Training And Development Barometer for Effective Transformation of Organizational Commitment and Overall Performance in Banking Sectors of KPK, Pakistan: Qualitative study of Workforce of Bank of Khyber, International Journal of Academic Research in Business and Social Sciences, 6(6), 246-267.

\section{(c) (i)}

(C) 2021 by authors. Content on this article is licensed under a Creative Commons Attribution 4.0 International license. (http://creativecommons.org/licenses/by/4.0/). 